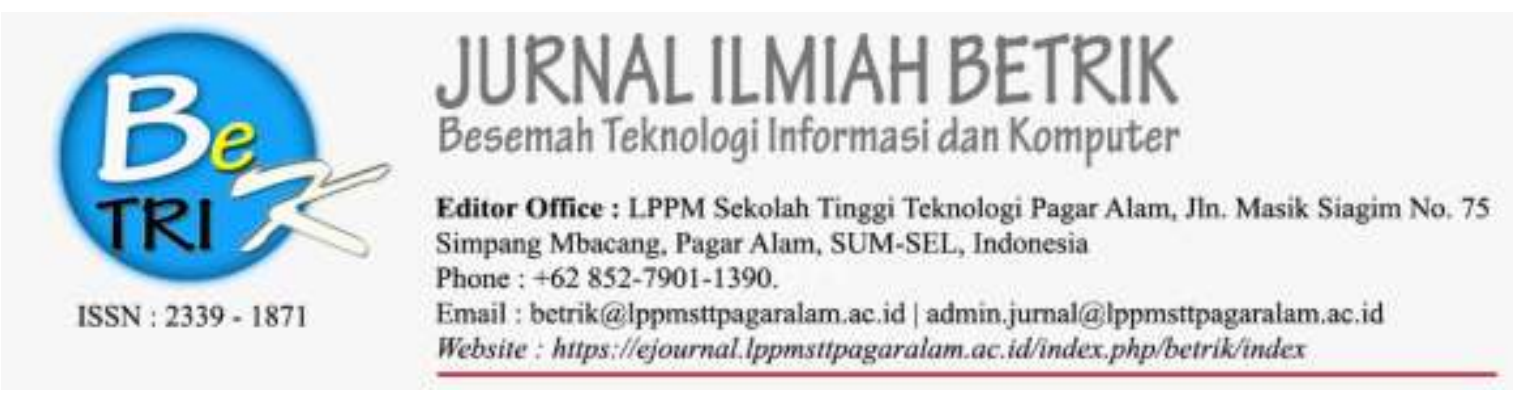

\title{
SISTEM PAKAR DIAGNOSA AWAL PENYAKIT GINJAL BERBASIS WEB MENGGUNAKAN PHP DAN MYSQL
}

\author{
Buhori Muslim ${ }^{1}$, Yadi ${ }^{2}$, Madi Harta ${ }^{3}$. \\ ${ }^{123}$ Sekolah Tinggi Teknologi Pagar Alam \\ Jalan Masik Siagim No.75 Simpang Mbacang Kec. Dempo Tengah, Pagar Alam \\ Sur-el : buhori45@yahoo.com ${ }^{1}$, madyharta28@ gmail.com²
}

\begin{abstract}
The design of expert systems for diagnosis of kidney disease is to build an expert system to diagnose kidney disease that provides information on diseases of the kidney through diagnosis of symptoms felt by sufferers with Web-based programming. Currently, if people want to diagnose with doctors to hospital or other health centers and have to wait their turn or queue to consult with doctors, to facilitate the consultation process needs a system that allows people to consult quickly, precisely and accurately. In designing this system using PHP and mysql programming language. The type of data collection obtained from the place of research, interviews with an expert, books and other literature. The method used in system development is Extreme Programming method which consists of Planning, Design, Coding, Test and Release. And the results of this design is to produce a system that provides information about kidney disease and help diagnose the disease through symptoms experienced.
\end{abstract}

Keywords: Expert System, Diagnosis, Kidney, Forward Chaining.

\begin{abstract}
Abstrak: Rancangan sistem pakar diagnosa penyakit ginjal ini merupakan untuk membangun sistem pakar untuk mendiagnosa penyakit ginjal yang memberikan informasi penyakitpenyakit pada ginjal melalui diagnosa gejala-gejala yang dirasakan penderita dengan pemrograman berbasis Web. Saat ini jika masyarakat ingin melakukan diagnosa dengan dokter harus ke rumah sakit atau pusat kesehatan lainnya dan harus menunggu giliran atau mengantri untuk berkonsultasi dengan dokter, untuk mempermudah proses konsultasi perlu adanya sistem yang memudahkan masyarakat untuk melakukan konsultasi dengan cepat, tepat dan akurat. Pada perancangan sistem ini menggunakan bahasa pemrograman PHP dan mysql. Adapun jenis pengumpulan data yang di peroleh dari tempat penelitian, wawancara dengan seorang pakar, buku dan literatur lainnya. Metode yang di gunakan dalam pengembangan sistem adalah metode Extreme Programming yang terdiri dari Planning, Design, Coding, Test dan Release. Dan hasil dari perancangan ini adalah menghasilkan sistem yang memberikan informasi tentag penyakit ginjal dan membantu mendiagnosa penyakit melalui gejala yang dialami.
\end{abstract}

Kata Kunci : Sistem Pakar, Diagnosa, Ginjal, Forward Chaining.

\section{PENDAHULUAN}

Perkembangan teknologi yang sangat pesat dapat dimanfaatkan dalam berbagai bidang kehidupan, termasuk dalam dunia medis yang dapat membantu dokter dalam mendiagnosa gejala penyakit yang dialami 
oleh manusia dan membantu pekerjaan manusia secara cepat, tepat dan akurat. Pada umumnya pasien yang ingin melakukan pemeriksaan atau mengetahui penyakit yang dideritanya harus datang ke Rumah sakit, Puskesmas atau pusat kesehatan lainnya, dan seorang pasien masih harus mengantri atau menunggu giliran untuk diperiksa. Namun dengan kemajuan teknologi, seorang pasien cukup membuka komputer untuk mengetahui penyakitnya. Sistem pakar adalah suatu program komputer yang dirancang untuk mengambil keputusan seperti keputusan yang diambil oleh seorang atau beberapa orang pakar (Latumakulita, 2012). Dalam hal ini kemampuan seorang pakar akan diimplementasikan kedalam sistem komputer dengan menggunakan metode tertentu, kemampuan pakar yang diimplementasikan ke dalam sistem komputer yaitu kemampuan pakar dalam mendiagnosa penyakit yang diderita oleh pasien yang diketahui melalui pertanyaan yang diinputkan ke dalam sistem komputer, pertanyaan yang di ajukan yaitu tentang gejala-gejala yang di alami oleh user, lalu sistem secara otomatis akan melakukan kalkulasi dan menarik kesimpulan berdasarkan jawaban dari pertanyaan dari gejala-gejala yang dialami. Dengan meng implementasikan kemampuan pakar ke dalam sistem komputer, user dapat melakukan konsultasi terhadap penyakitnya dimanapun dan kapanpun hanya dengan melakukan interface dengan komputer. Tujuan utama sistem pakar bukan untuk menggantikan peran seorang pakar atau ahli tetapi hanya untuk memasyarakatkan pengetahuan dan pengalaman para pakar membantu masyarakat mengetahui penyakitnya dengan mudah dan cepat. Sistem pakar dirancang agar dapat menyelesaikan suatu permasalahan tertentu dengan meniru kerja para ahli. Dengan sistem pakar, orang awam bisa menyelesaikan masalah yang rumit yang sebenarnya hanya bisa diselesaikan dengan bantuan para ahli. Di Indonesia Penyakit Ginjal merupakan salah satu penyakit yang sering dijumpai atau penyakit yang paling banyak diderita selain penyakit diabetes, kanker dan penyakit jantung. Berdasarkan data dari Rumah Sakit Umum Daerah (RSUD) Besemah Kota Pagar Alam bahwa jumlah penderita Penyakit Ginjal yang ditangani oleh RSUD Besemah tahun 2016 sebanyak 385 pasien. Angka ini meningkat dari tahun 2015 yang hanya berjumlah 181 pasien. Dengan adanya Sistem Pakar Diagnosa Penyakit Ginjal diharapkan dapat memberikan informasi kepada masyarakat tentang penyakit ginjal dan diharapkan dapat mengurangi jumlah penderita Penyakit Ginjal khususnya dikota Pagar Alam.

\section{METODOLOGI PENELITIAN}

Penulisan ini tentu memerlukan data akurat terutama yang erat kaitannya dengan objek penyakit ginjal ini. Oleh karena itu di perlukan metode penelitian agar mendapatkan data yang objektif (Suryana, 2010). Metode Penelitian adalah prosedur atau langkahlangkah dalam mendapatkan pengetahuan ilmiah atau ilmu. jadi metode penelitian merupakan cara sistematis untuk menyusun ilmu pengetahuan.

\section{a. Metode Studi Pustaka}

Metode ini di laksanakan dengan melakukan studi kepustakaan yaitu membaca 
buku-buku dan artikel-artikel atau jurnal penelitian yang berkaitan dengan metodemetode maupun objek yang di teliti. untuk mendukung penulisan ini.

\section{b. Metode Observasi}

Yaitu pengumpulan data yang dilakukan dengan pengamatan secara langsung di Rumah Sakit Umum Daerah (RSUD) Besemah Kota Pagar Alamuntuk mendapatkan data-data dan fakta yang di perlukan.

\section{c. Metode wawancara}

Yaitu pengumpulan data yang dilakukan dengan cara tanya jawab langsung terhadap seorang ahli dalam hal ini seorang dokter, agar mendapat data dan fakta yang akurat.

\subsection{Metode Pengembangan Sistem}

Metode pengembangan sistem menggunakan metode pengembangan Extreme Programming (Mercydian Pangkey, 2016). yaitu:

\section{Planning}

Proses pengumpulan informasi kemudian menyeleksinya (dibantu oleh seorang pakar) sehingga sesuai dengan kebutuhan sistem yang akan dibangun. Pada penelitian ini pakar yang dimaksud adalah seorang dokter.

\section{Design}

Proses perancangan sistem yang akan dibuat oleh peneliti

\section{Coding}

Proses perancangan dalam bahasa pemrograman, sehingga proses input menghasilkan output melalui sebuah sistem yang dibangun

\section{Test}

Merupakan fase ujicoba dari sistem yang dibangun peneliti. Hal ini dilakukan untuk mengetahui sudah terpenuhi atau belum kebutuhan sistem yang dibangun.

\section{Release}

Ini bagian terakhir dari metode pengembangan sistem dipakai peneliti. Dalam tahap ini tidak ada lagi stories (data) dari user yang diimplementasikan sehingga semua kebutuhan sistem dianggap sudah terpenuhi. Tidak ada lagi perubahan arsitektur, Perancangan, dan pengkodean.

\subsection{Sistem}

Sistem kumpulan dari sub sistem, elemen, prosedur, saling berintegrasi untuk mencapai tujuan tertentu, seperti informasi, target atau goal. Karakter suatu sistem terdiri dari component, boundary, input, process dan output, objectives, goal (Hapzi Ali, 2010).

\subsubsection{Sistem Pakar}

Sistem pakar itu salah satu cabang dari Artificial Inteligence yang membuat penggunaan secara luas knowledge yang khusus untuk penyelesaian masalah tingkat manusia yang pakar. Pakar adalah orang yang mempunyai keahlian di bidang tertentu, yaitu pakar yang mempunyai knowledge atau kemampuan khusus yang orang lain tidak mengetahui atau mampu dalam bidang yang dimilikinya (Arhami, 2005).

\subsubsection{Ginjal}

Ginjal merupakan bagian sebuah sistem yang disebut sistem kemih. Sistem kemih terdiri atas dua buah ginjal, dua pipa yang menghubungkan ginjal dengan kandung kemih, sebuah kandung kemih, serta sebuah pipa yang menghubungkan kandung kemih 
dengan dunia luar. Pipa yang menghubungkan ginjal dengan kandung kemih disebut ureter. Sedang pipa penghubung kandung kemih dengan dunia luar disebut uretra (Dharma, 2015).

\subsubsection{Penyakit Ginjal}

Penyakit ginjal merupakan hilangnya fungsi ginjal yang mengalami penurunan hingga 10\%. Tahap paling parah, penyakit ginjal berujung pada gagal ginjal atau bahkan End-Stage Renal Disease (ESRD). Penurunan fungsi ini membuat ginjal tak mampu lagi menyaring pembuangan elektrolit tubuh serta menjaga keseimbangan cairan dan zat kimia tubuh. Penyakit ginjal tidak memandang usia maupun jenis kelamin, meskipun demikian, prevalensi penderita anak tergolong sedikit. Penyakit ini biasanya menyerang tanpa di sadari penderita. Tidak sedikit penderita yang kerap mengabaikannya karena menganggapnya sebagai penyakit biasa (Dharma, 2015).

\subsubsection{Use Case Diagram}

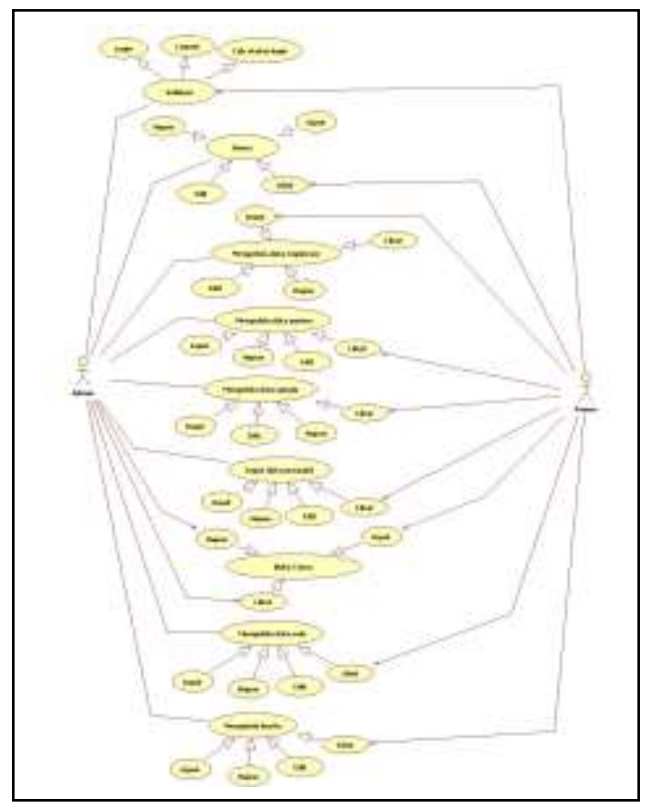

Gambar 1.Use Case Diagram

\subsubsection{Class Diagram}

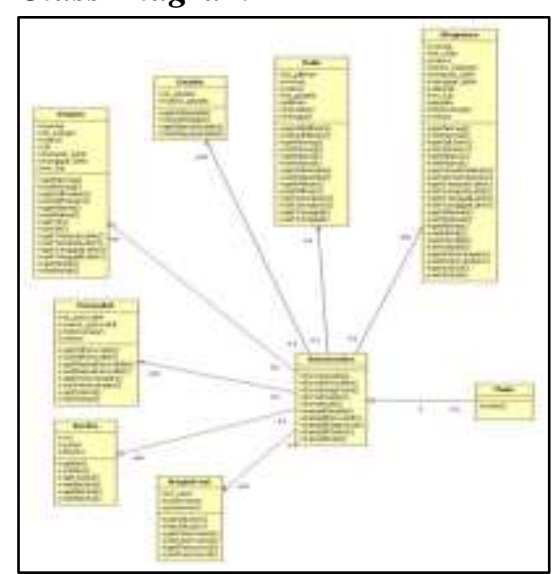

Gambar 2 Class Diagram

\subsubsection{Sequence diagram User}

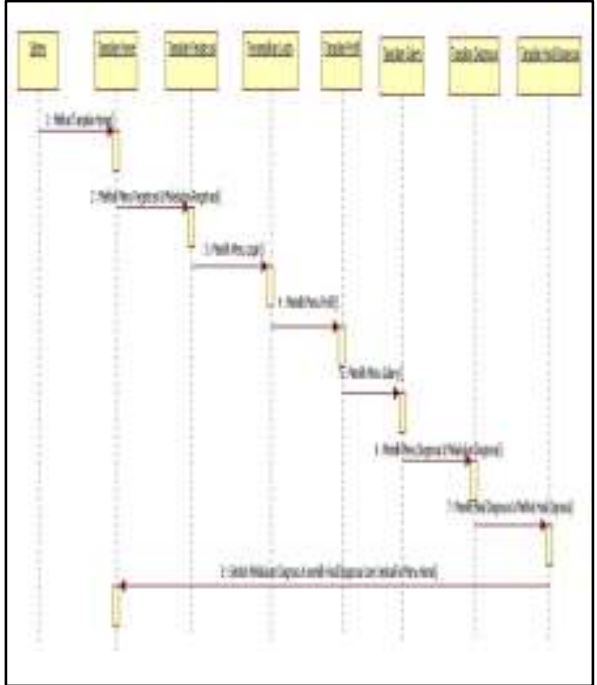

Gambar 3 Sequence diagram User

\subsubsection{Sequence Diagram Admin}

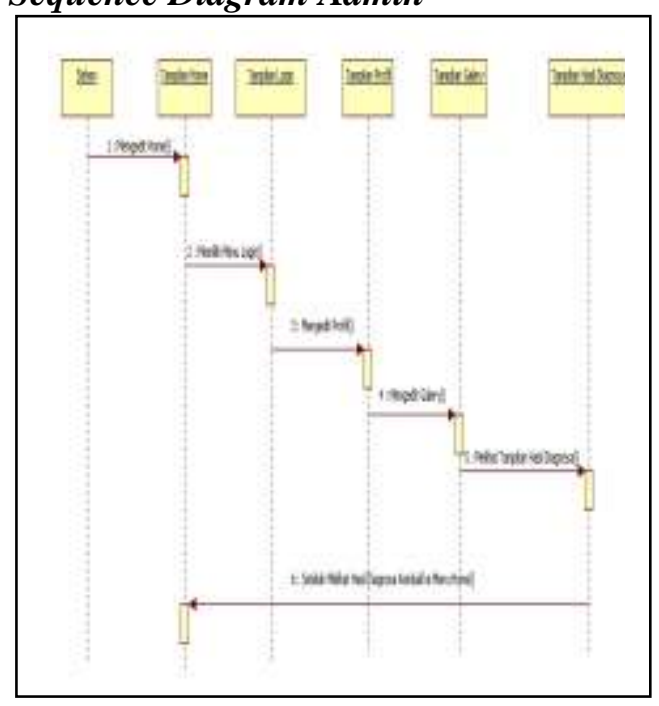

Gambar 4 Sequence Diagram Admin 


\subsubsection{Statechart Diagram}

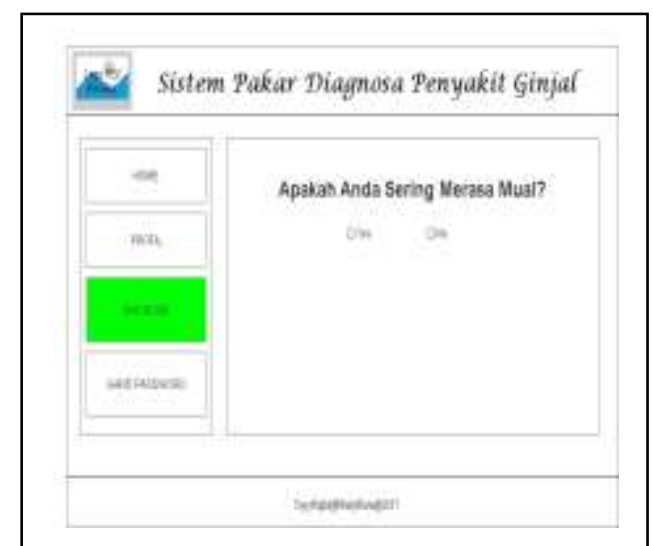

\subsubsection{Activity Diagram User}

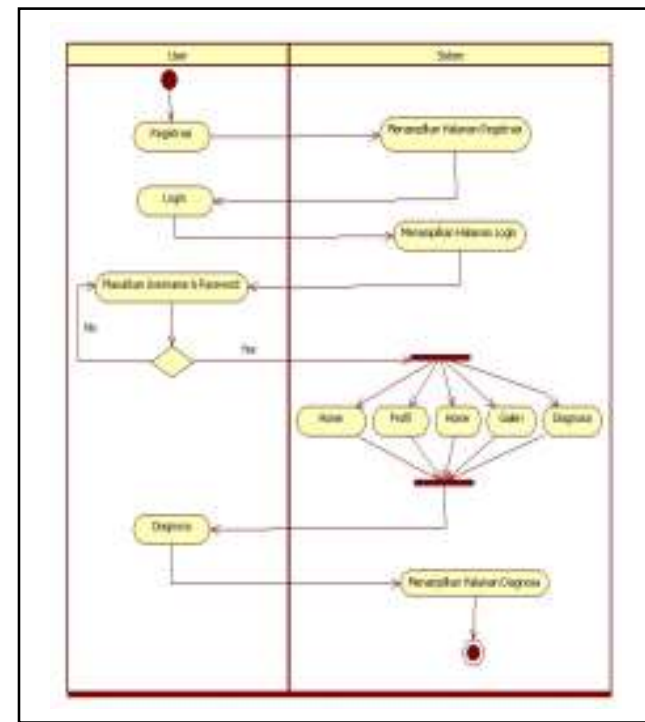

Gambar 6 Activity Diagram User

\subsubsection{Activity Diagram Admin}

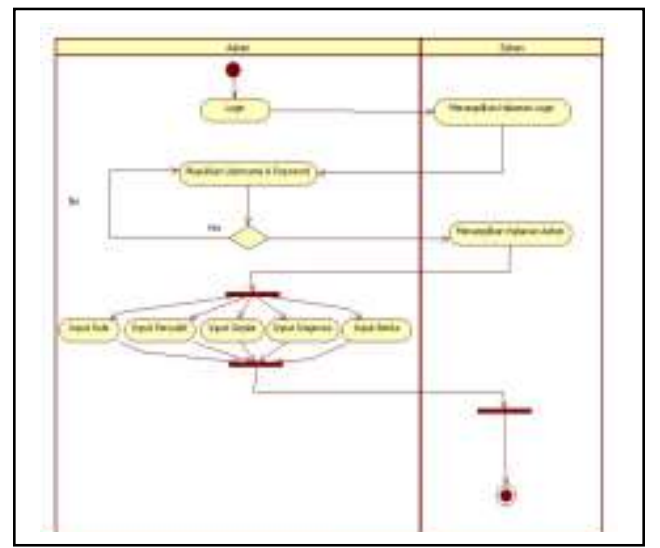

Gambar 7 Activity Diagram Admin

\subsection{Rancangan Halaman Utama}

Merupakan halaman utama (Home) pada saat User maupun admin membuka Sistem Pakar.

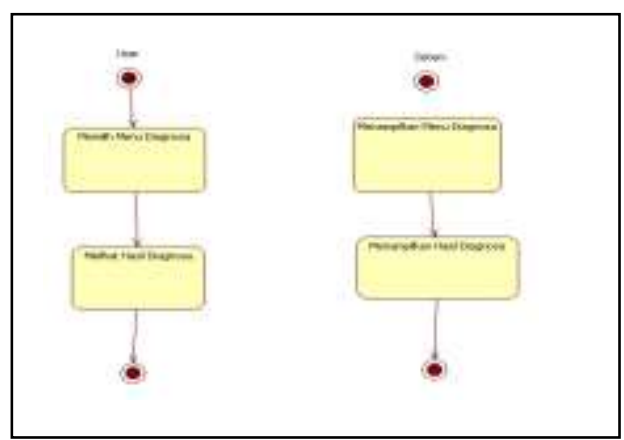

\section{Gambar 8 Halaman Utama (Home)}

\subsubsection{Rancangan Halaman Registrasi}

Halaman ini merupakan halaman registrasi atau pendaftaran User untuk mendapatkan Username dan Password agar bisa $\log$ in ke dalam sistem pakar.

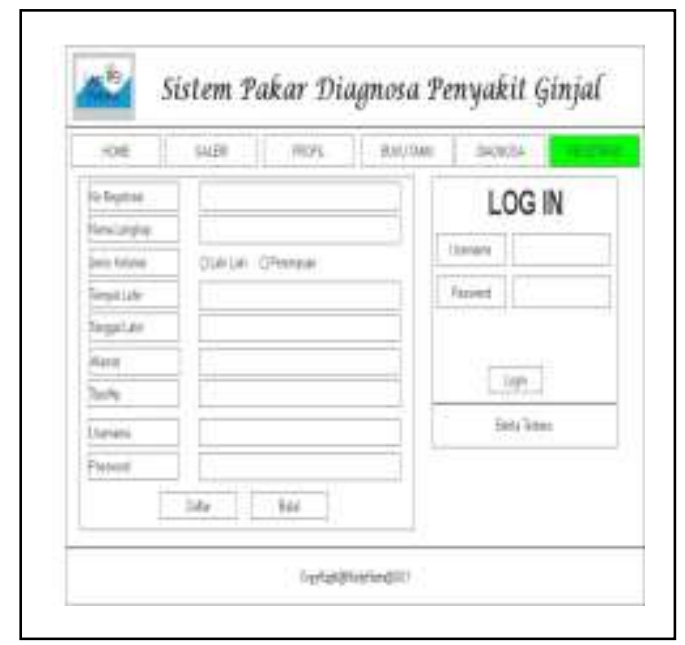

\section{Gambar 9 Halaman Registrasi}

\subsubsection{Rancangan Halaman Diagnosa}

Halaman ini berfungsi untuk menampilkan pertanyaan-pertanyaan mengenai gejala yang terdapat pada Penyakiit Ginjal, setelah itu akan mendapat informasi berupa hasil diagnosa dan solusinya. 


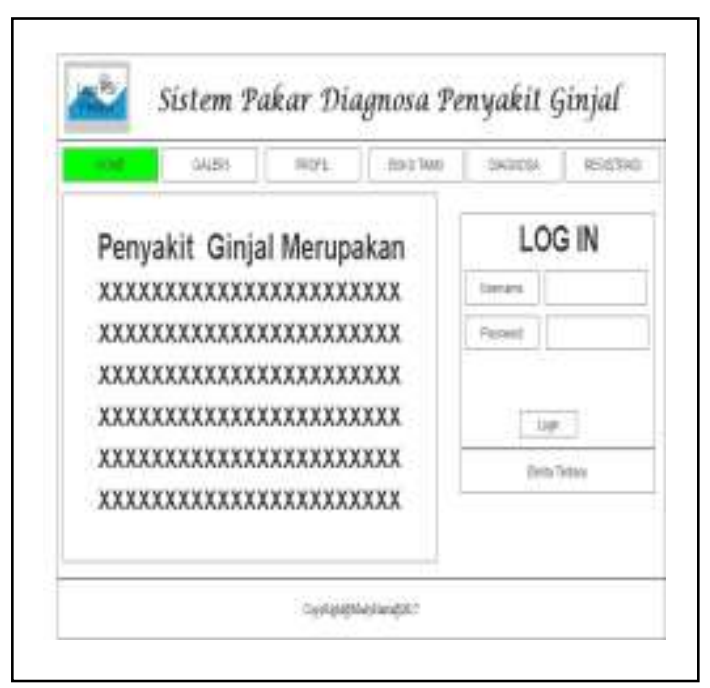

\section{Gambar 10 Halaman Diagnosa}

\subsubsection{Rancangan Halaman Hasil Diagnosa}

User melakukan Diagnosa, sistem akan menampilkan hasil dari diagnosa tersebut di Halaman Hasil Diagnosa, di halaman ini User juga terdapat pilihan untuk melakukan konsultasi ulang dan mencetak hasil Konsultasi.

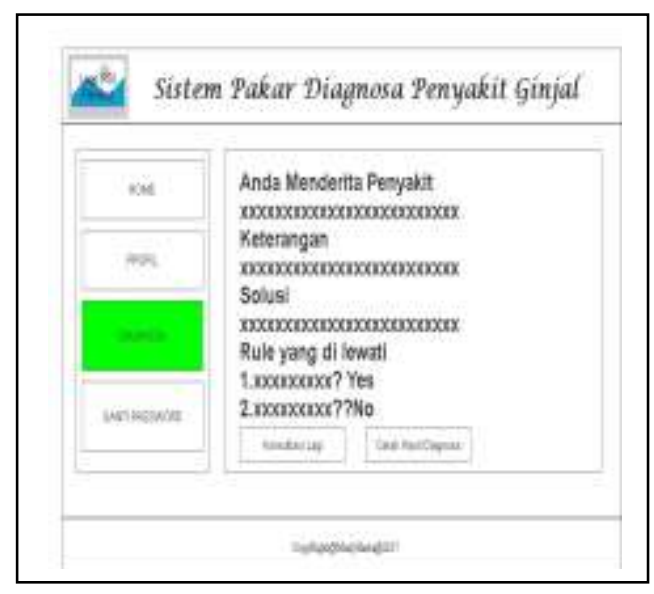

Gambar 11 Halaman Hasil Diagnosa

\section{HASIL DAN PEMBAHASAN}

\subsection{Hasil}

Hasil dari perancangan sistem pakar diagnosa penyakit ginjal adalah suatu sistem yang memberikan informasi mengenai penyakit ginjal dan membantu user untuk mendiagnosa penyakit ginjal melalui gejalagejala penyakit ginjal yang di inputkan kedalam sistem, dengan adanya sistem pakar ini dapat membantu masyarakat untuk mendiagnosa penyakit ginjal tanpa datang ke rumah sakit atau pusat kesehatan lainnya, dengan mengakses sistem ini masyarakat juga tidak perlu megeluarkan biaya yang besar untuk melakukan diagnosa, masyarakat hanya perlu melakukan registrasi ke dalam sistem untuk mendapatkan username dan password dan user dapat login ke dalam sistem untuk melakukan diagnosa dan melihat hasil diagnosa dengan cara mengakses website sistem pakar dengan alamat madiharta.hol.es.

\subsection{Pembahasan}

\subsubsection{Halaman Menu Home}

Halaman ini merupakan halaman pertama yang akan muncul ketika sistem di buka, halaman ini berisi sekilas informasi mengenai ginjal dan penyakit ginjal, di dalam halaman ini juga terdapat beberapa menu yang dapat diakses seperti, galeri, profil, buku tamu, diagnosa, registrasi dan form login.

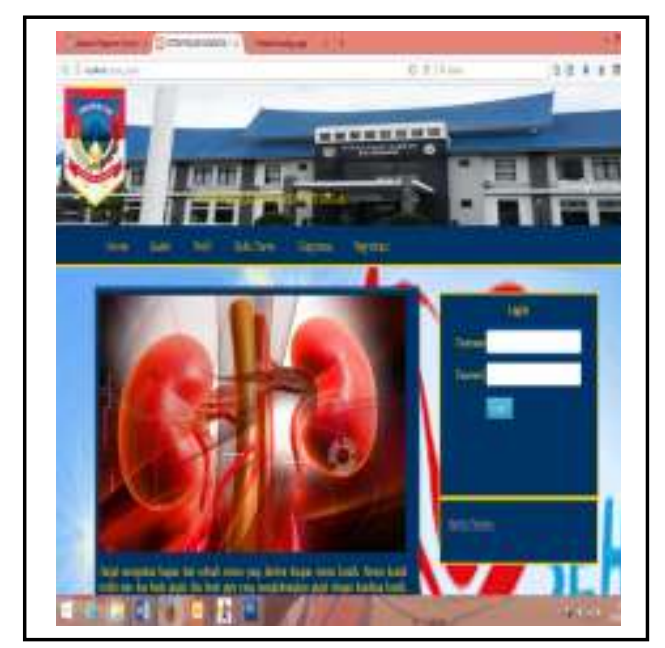

Gambar 12. Halaman Home 


\subsubsection{Halaman Registrasi}

Halaman ini merupakan halaman registrasi atau pendaftaran User untuk mendapatkan Username dan Password agar bisa $\log$ in ke dalam sistem pakar.

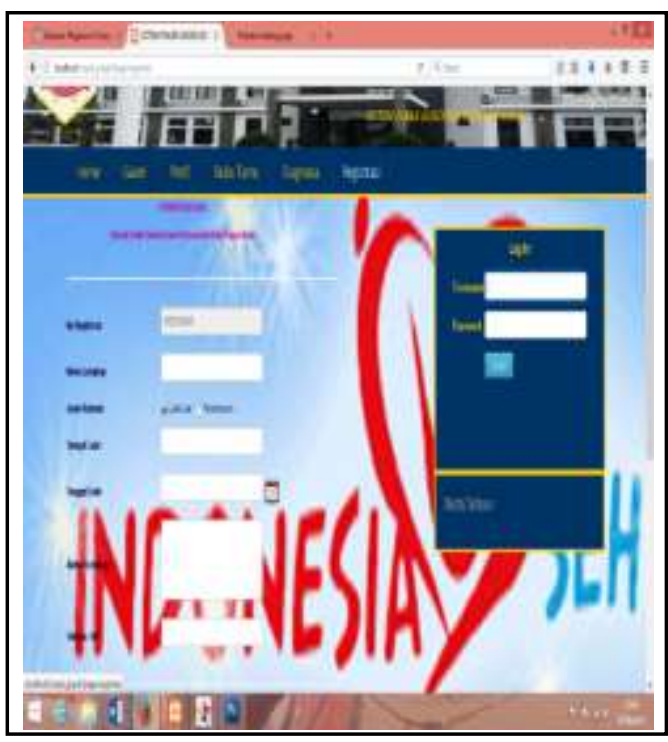

Gambar 13 Halaman Registrasi

\subsubsection{Halaman Diagnosa}

Halaman ini menampilkan pertanyaanpertanyaan mengenai gejala yang terdapat pada Penyakiit Ginjal, setelah itu akan mendapat informasi berupa hasil diagnosa dan solusinya.

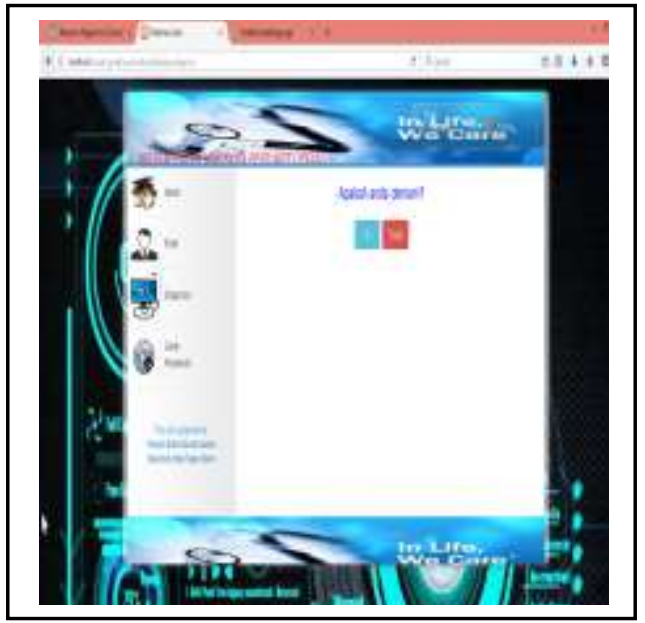

Gambar 14. Halaman Diagnosa

\subsubsection{Halaman Hasil Diagnosa}

User melakukan Diagnosa, maka sistem akan menampilkan hasil dari diagnosa tersebut di Halaman Hasil Diagnosa, di halaman ini User juga terdapat pilihan untuk melakukan konsultasi ulang dan mencetak hasil Konsultasi

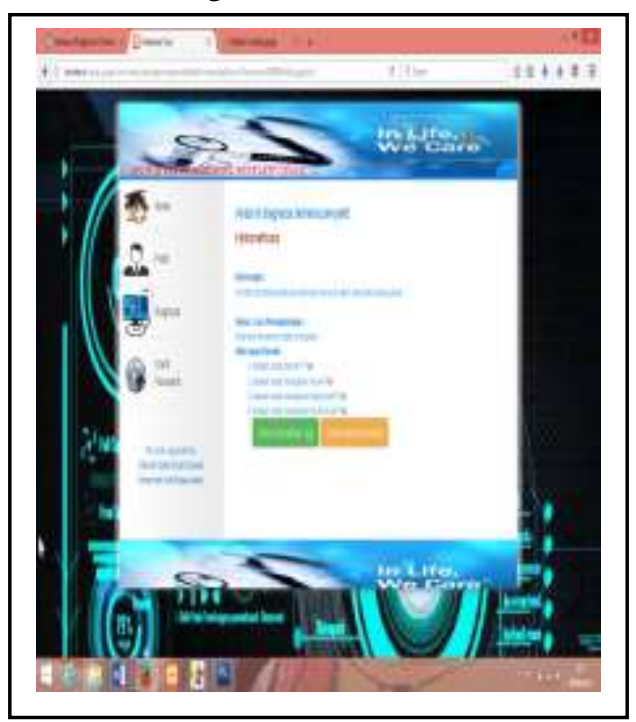

Gambar 15 Halaman Hasil Diagnosa

\section{KESIMPULAN DAN SARAN}

\subsection{Kesimpulan}

Kesimpulan yang didapat diambil dari Penelitian yang berjudul Sistem Pakar Diagnosa Penyakit Ginjal Berbasis Web adalah Pada penelitian ini dihasilkan Sistem Pakar Diagnosa Penyakit Ginjal Berbasis Web yang dapat memberikan kemudahan masyarakat mendiagnosa penyakit ginjal, yang memberikan informasi penyakit-penyakit pada ginjal melalui diagnosa gejala-gejala yang dirasakan oleh penderita dengan pemrograman berbasis Web.

\subsection{Saran}

Sistem pakar diagnosa penyakit ginjal berbasis web ini merupakan sistem yang masih mempunyai banyak kekurangan. Oleh karena itu, perlu dilakukan penyempurnaan dan 
pengembangan sistem yang diharapkan dapat menjadikan sistem menjadi lebih baik lagi diantaranya:

1. Sistem yang dapat mendiagnosa penyakit ginjal dalam ruang lingkup yang lebih luas dengan jenis penyakit ginjal yang lebih kompleks.

2. Sistem yang dapat merekapitulasi data pengunjung sistem dengan lebih sempurna.

\section{DAFTAR PUSTAKA}

Abdul Kadir. (2008). Tuntunan Praktis Belajar Database Menggunakan MySQL. Yogyakarta: C.V ANDI OFFSET (Penerbit ANDI).

Desy Fernanda Putri Aria, N. S. (2009). sistem pakar untuk mendiagnosa penyakit ginjal menggunakan metode forward chaining. jurnal online ICT STMIK IKMI VOL 1 NO 2 Edisi Desember 2009, 1.

Hannie Qalbinah Syaiful, F. O. (2014). Hubungan umur dan lamanya hemodialisis dengan status gizi pada penderita penyakit Ginjal Kronik yang mengalami Hemodialisis. jurnal kesehatan Andalas, 1-7.

Hapzi Ali, Tonny Wangdra. (2010). Sistem Informasi Bisnis. Praninta Offset.

Kusrini. (2008). Aplikasi Sistem Pakar. Yogyakarta: Penerbit Andi.

Latumakulita, L. A. (2012). Sistem Pakar Diagnosa Penyakit Anak Menggunakan Certainty Factor. Jurnal Ilmiah Sains Vol. 12 No. 2, 1-7.

MADCOMS. (2008). Adobe Dreamweaver CS3 dan PHP. Yogyakarta: Penerbit ANDI.

Muhammad Arhami. (2005). Konsep Dasar Sistem Pakar. Yogyakarta: Penerbit Andi.

Mercydian Pangkey, V. P. (2016). Sistem Pakar Pendeteksi Kerusakan Handphone Berbasis Android. Jurnal Teknik Infor3qlmatika, 2.

Muhammad Arhami. (2005). Konsep Dasar Sistem Pakar. Yogyakarta: Penerbit Andi.
Munawar. (2005). Permodelan Visual Dengan $U M L$. Yogyakarta: Graha Ilmu Yogyakarta.

Nita Merlina, Rahmat Hidayat. (2012). Perancangan Sistem Pakar. Bogor: Ghalia Indonesia.

Nugroho. (2006). Pengertian UML. elib.unikom.ac.id.

Ridi Ferdiana. (2012). Rekayasa Perangkat Lunak Yang Dinamis Dengan Global Extreme Programming. Yogyakarta: Penerbit Andi.

Rismawati. (2013). Perancangan Aplikasi Sistem Pakar Untuk Mendiagnosa Penyakit Ginjal Dengan Metode Dempster Shafer. Pelita Informatika Budi Darma ISSN : 2301-9425, 2.

Sidik, Betha , Husni Iskandar Pohan. (2010). pemrograman web dengan HTML. Bandung: Penerbit Informatika.

Sri Yastita, Y. D. (2012). Sistem Pakar pada penyakit kulit menggunakan metode Certainty Factor berbasis Web. Seminar Nasional Teknologi Informasi, Komunikasi dan Industri (SNTIKI) 4 ISSN : 2085-9902, 1-10.

Suryana. (2010). Metodologi Penelitian. Model Praktis Penelitian Kuantitatif dan Kualitatif, 19.

Suyanto. (2011). Artificial Intelligence. Bandung: Penerbit Informatika Bandung.

Taringan, Feriana A. (2014). Sistem Pakar Untuk Mendiagnosa Penyakit Ginjal dengan Metode Backward Chaining. Jurnal TIMES, Vol III No 2:25-29 ISSN : 2337 - 3601, 1-5.

Wahana Komputer. (2009). PHP Programming. Semarang: Penerbit Andy. 